\title{
Estimativa da evapotranspiração real em área de relevo acidentado utilizando o SEBAL
}

Real evapotranspiration estimate in mountain terrain area using SEBAL

\author{
André Luiz Profeta, ${ }^{1}$ \\ Sergio Donizete Faria, ${ }^{2}$ \\ Hemlley Maria Acioli Imbuzeiro ${ }^{3}$
}

Recebido em novembro de 2017.

Aprovado em outubro de 2018.

\begin{abstract}
RESUMO
A evapotranspiração é um processo de redistribuição tanto de água como de energia na interface superfície-atmosfera, sendo uma variável essencial para aplicação em modelos hidrológicos, biofísicos e climáticos. Esses modelos contribuem para uma gestão consistente dos recursos hídricos, seja em escala local, regional, ou global; em recortes artificiais (agricultura e pastagem) ou em ambientes naturalmente definidos, como bacias hidrográficas e biomas. O presente estudo tem como objetivo estimar a evapotranspiração real horária e diária em área de relevo acidentado, utilizando o Surface Energy Balance Algorithms for Land (SEBAL) a partir de imagens do satélite Landsat 8 e dados meteorológicos. Assim, são executados dois modelos para a Unidade de Planejamento e Gestão de Recursos Hídricos do Rio Piranga (UPGRH DO1) - Minas Gerais: sem correção para a influência do relevo (Modelo 1) e com correção para a influência do relevo (Modelo 2). Com a aplicação do SEBAL, o fluxo de calor latente $(\lambda E T)$ é estimado como um resíduo da equação simplificada do balanço de energia. A partir do $\lambda E T$, que corresponde à energia empregada para o processo de evapotranspiração, é estimada a evapotranspiração real horária e, utilizando a fração evaporativa, a evapotranspiração real diária. Os resultados de evapotranspiração obtidos permitem evidenciar sua variabilidade espacial na UPGRH DO1 e o conhecimento da contribuição de vapor d'água para a atmosfera considerando os tipos de cobertura e uso da terra na área sob investigação. A partir da comparação dos valores estimados com a evapotranspiração de referência $\left(E T_{0}\right)$, calculada pelo método Penman-Monteith padrão FAO, e com a evapotranspiração da cultura $\left(E T_{c}\right)$ do eucalipto, a estimativa com os dois modelos se mostrou
\end{abstract}

\footnotetext{
1Universidade Federal de Minas Gerais (UFMG), Instituto de Geociências (IGC). Programa de Pósgraduação em Análise e Modelagem de Sistemas Ambientais, Brasil. E-mail: andreluiz.geo@gmail.com ${ }^{2}$ Universidade Federal de Minas Gerais (UFMG), Instituto de Geociências (IGC), Departamento de Cartografia, Brasil. E-mail: fariamaracai@yahoo.com.br

${ }^{3}$ Universidade Federal de Viçosa (UFV), Departamento de Engenharia Agrícola, Brasil. E-mail: hewlley@hotmail.com
} 
consistente. A estimativa com Modelo 2 tende a apresentar valores inferiores aos do Modelo 1. Em ambos os modelos, ficou evidente a influência da vegetação no particionamento dos fluxos de energia na superfície da Terra.

PALAVRAS-CHAVE: evapotranspiração, sensoriamento remoto, SEBAL.

\begin{abstract}
Evapotranspiration is one of the processes that redistributes water and energy in the Earth system. This is an essential variable for hydrological, biophysical and climate models, which contributes for the sound management of water resources in the local, regional and global scales, as well as in natural (watersheds and biomes) or artificial systems (agriculture and pasture land). This study aims at estimating the daily and hourly real evapotranspiration in a mountain terrain using the Surface Energy Balance Algorithms for Land (SEBAL), Landsat 8 imagery and meteorological data. Two models were made in the Piranga River Water Resources Management Unit (UPGRH DO1): firstly, without considering the influence of the relief (Model 1); secondly, considering it (Model 2). Applying SEBAL, the latent heat flux $(\lambda E T)$ is estimated as a residual of the simplified energy balance equation. From the $\lambda E T$, which corresponds to the energy used in the evapotranspiration process, the hourly real evapotranspiration is calculated. Then, using the evaporative fraction, the daily real evapotranspiration is calculated. The results show the evapotranspiration spatial variability and the different land cover in the area water vapor contribution to the atmosphere. Comparing the results with the reference evapotranspiration $\left(E T_{0}\right)$ calculated by the FAO Penman-Monteith equation and the crop evapotranspiration $\left(E T_{c}\right)$ from the Eucalyptus plantation, the results of the two models were consistent. Also, the results from the second model tend to be below the results of the first model. In both models, the effect of vegetation in the energy flux across the surface is evident.
\end{abstract}

KEYWORDS: evapotranspiration, remote sensing, SEBAL.

$$
* * *
$$

\title{
Introdução
}

A evapotranspiração (ET) é um dado de entrada para modelos hidrológicos, biofísicos e climáticos, sendo um parâmetro fundamental do comportamento do ciclo da água, na medida em que representa a "perda" de água do solo para a atmosfera. Seu conhecimento tem implicações importantes para a agricultura, permitindo uma gestão eficiente do uso da água nos processos de irrigação. Em ambientes mais complexos e heterogêneos, como o estudo de bacias hidrográficas, a evapotranspiração pode ser utilizada, por exemplo, para conhecer a contribuição de vapor d'água 
para a atmosfera de acordo com a cobertura vegetal, condição que está associado ao estresse hídrico da vegetação.

A evapotranspiração engloba os processos de evaporação dos corpos d'água, do conteúdo hídrico presente no solo e interceptada pelas plantas na superfície terrestre, mais os processos de transpiração da cobertura vegetal. Ela pode ser expressa em milímetros $(\mathrm{mm})$ por unidade de tempo e em termos de energia recebida por unidade de área, referida como calor latente de vaporização $-\lambda$ (ALLEN et al., 1998).

Com relação aos mecanismos de estimativa da evapotranspiração, Pereira, Sediyama e Villa Nova (2013) descrevem diferentes métodos. Os métodos de campo (lisímetro de pesagem, tanque de evaporação classe A) correspondem a medidas diretas. Já os métodos que utilizam o perfil atmosférico consideram as leis da física que regem a interação atmosferasuperfície, bem como o balanço de energia: método aerodinâmico, razão de Bowen; método do balanço de energia, métodos combinados.

Todos esses métodos possuem formulações robustas, porém fornecem apenas estimativas pontuais. Esse fato tem motivado a proposição de métodos que utilizam dados de sensoriamento remoto, os quais permitem uma visão da evapotranspiração distribuída no espaço, sem a necessidade de computar os complexos processos hidrológicos como, por exemplo, da dinâmica hidráulica do solo (ALLEN, TASUMI e TREZZA, 2002).

Compreendendo as leis físicas que contemplam o processo de aquisição em nível orbital, é possível construir relações entre as medidas da radiação eletromagnética que são refletidas ou emitidas pelos alvos e a ocorrência do fenômeno, seja na superfície da Terra ou na atmosfera, procurando sempre compreender sua distribuição no espaço (MATHER, 2004).

Uma forma de estimar a evapotranspiração distribuída no espaço é através do uso do Surface Energy Balance Algorithms for Land - SEBAL (BASTIAANSSEN et al., 1998a; 1998b), que tem como objetivo a possibilidade de aplicação em escalas regionais e ambientes heterogêneos sem a 
necessidade de dispendiosas medidas de campo para fins de regionalização das densidades de fluxos de superfícies e indicadores de umidade do solo.

Estudos com a aplicação do SEBAL têm sido realizados em diferentes partes do mundo: China (ZHOU et al., 2014), Espanha (JIMÉNEZ-BELLO et al., 2015), Estados Unidos (STEELE et al., 2014; MKHWANAZI, CHÁVEZ e ANDALES, 2015), Iraque (JABER et al., 2016), Arábia Saudita (MAHMOUD e ALAZBA, 2016). No Brasil, também se encontram aplicações (SILVA et al. 2015; BORATTO, 2012; RUHOFF, 2011; TEIXEIRA et al., 2009; TEIXEIRA et al., 2008; NICÁCIO, 2008).

O SEBAL utiliza satélites multiespectrais de média e alta resolução que operam nas faixas do espectro na região do visível e do infravermelho termal. Nesse algoritmo, o fluxo de calor latente ( $\lambda E T)$ é estimado como um resíduo do balanço de energia simplificado, utilizando a Equação 1:

$$
\lambda E T=R_{n}-G-H
$$

em que, $\lambda E T$ é o fluxo de calor latente; $H$ é o fluxo de calor sensível no ar; $G$ é o fluxo de calor sensível no solo.

O saldo de radiação à superfície da Terra $\left(R_{n}\right)$ e o fluxo de calor no solo (G) são computados considerando relações diretas com os dados espectrais orbitais. O fluxo de calor sensível $(H)$ assume uma função linear entre a temperatura da superfície terrestre $\left(T_{s}\right)$ e o gradiente de temperatura do ar próximo à superfície. A partir do $\lambda E T$, que corresponde à energia empregada para o processo evapotranspirativo, é estimada a evapotranspiração real instantânea (horária) e, utilizando a fração evaporativa, a evapotranspiração real diária (ALLEN, TASUMI e TREZZA, 2002). A abordagem do balanço de energia se fundamenta na aplicação do princípio de conservação da energia aos fluxos de energia relacionados com a fonte de radiação e a interação desta com a superfície terrestre (PEREIRA, SEDIYAMA e VILLA NOVA, 2013).

$O$ presente estudo utiliza três abordagens ainda pouco exploradas em aplicações no Brasil, de acordo com a bibliografia consultada: i) como o SEBAL 
foi desenvolvido para utilização em terrenos planos, sua aplicação para terrenos acidentados é limitada. Porém, há mecanismos de correção para assimilar a influência do relevo na estimativa de alguns parâmetros, os quais foram adotados neste estudo; ii) em relação à escolha do sensor orbital, considerando os de maior aplicação no algoritmo, o Moderate Resolution Imaging Spectrometer (MODIS - TERRA e AQUA), Thematic Mapper (TM Landsat 5) e Enhanced Thematic Mapper Plus (ETM+ - Landsat 7), há sempre uma decisão entre resolução temporal e resolução espacial. Como há o interesse em fazer associações com a cobertura e uso da terra e, considerando que a área adotada para o estudo possui uma fragmentação da paisagem que não seria passível de ser identificada no MODIS, optou-se por utilizar imagens da série Landsat, especificamente do Landsat 8, com as quais não foi identificado, na literatura consultada, nenhum estudo de aplicação do SEBAL; iii) o algoritmo geralmente é aplicado para estudos de áreas agrícolas, sendo pouco explorado em estudos que consideram limites naturais, como de bacias hidrográficas ou biomas.

Assim, este trabalho tem como objetivo estimar a evapotranspiração real horária e diária em área de relevo acidentado, utilizando o SEBAL com imagens do satélite Landsat 8 e dados meteorológicos, buscando evidenciar sua variabilidade espacial para a Unidade de Planejamento e Gestão de Recursos Hídricos do Rio Piranga (UPGRH DO1) - Minas Gerais.

\section{1 Área de Estudo}

A área de estudo compreende a Unidade de Planejamento e Gestão de Recursos Hídricos do Rio Piranga (UPGRH DO1), localizada no estado de Minas Gerais e definida pela Deliberação Normativa 6/2002, do Conselho Estadual de Recursos Hídricos de Minas Gerais (CERH/Minas Gerais), segundo relatório do Instituto Mineiro de Gestão das Águas (IGAM, 2007).

A UPGRH DO1 (Figura 1) faz parte da bacia hidrográfica federal do rio Doce e se estende desde o rio Piranga até o Parque Estadual do Rio Doce 
(PERD), englobando a bacia hidrográfica dos rios Piranga, Carmo, Casca e Matipó, de acordo com a Fundação Estadual do Meio Ambiente (FEAM, 2015). Essa unidade ocupa uma extensão territorial de $17.571 \mathrm{~km}^{2}$ e abrange 77 municípios (total ou parcialmente), abrigando uma população de $\sim 1,3$ milhão de habitantes, de acordo com dados do Instituto Brasileiro de Geografia e Estatística - IBGE de 2010 (FEAM, 2015).

Figura 1 - Mapa de localização da área de estudo: UPGRH DO1, com o relevo ao fundo.

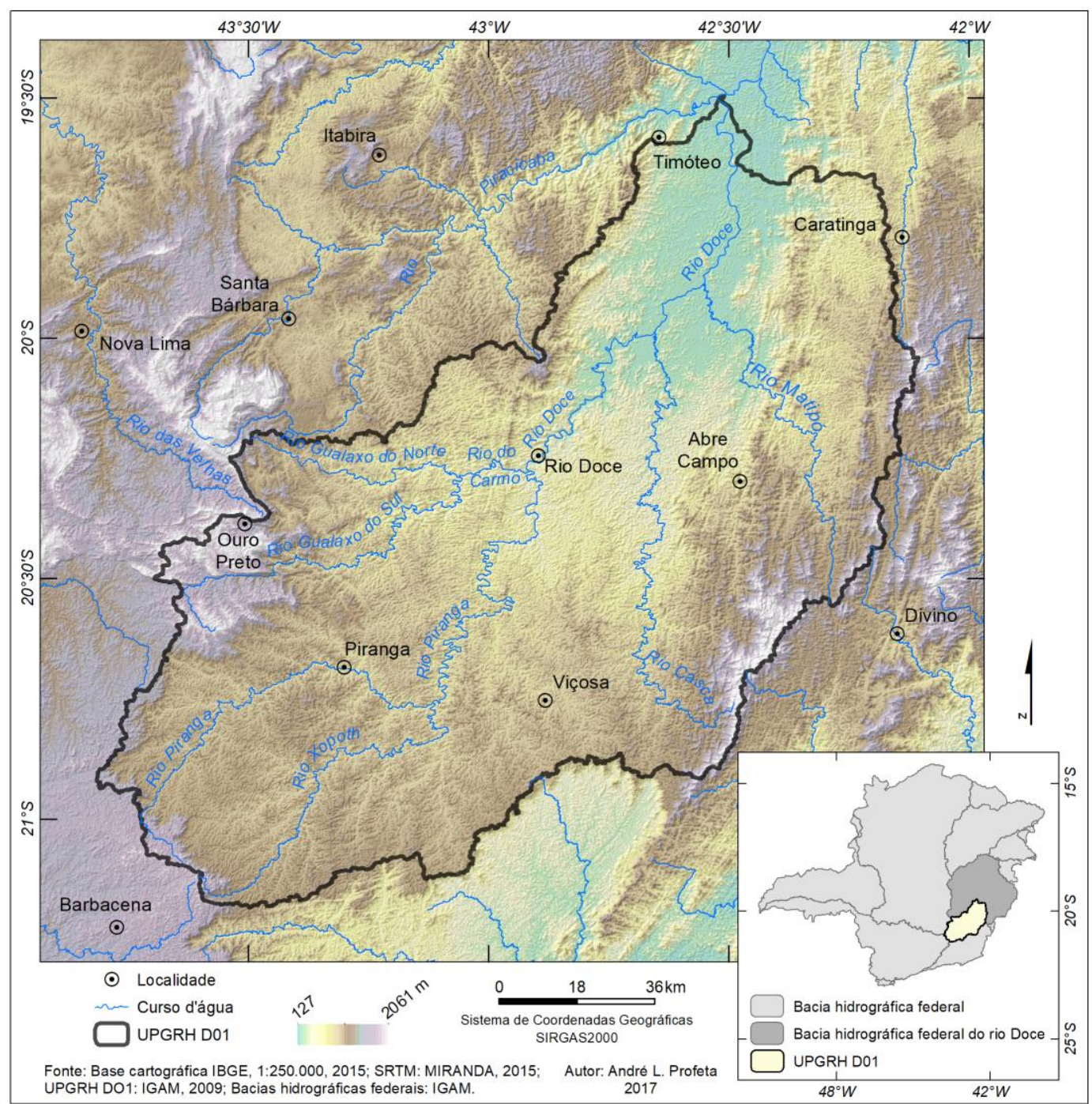

Fonte: Elaborada pelos autores.

Quanto à vegetação, a UPGRH DO1 está sobre a faixa de domínio da Mata Atlântica, sendo que as partes mais preservadas se encontram nas cabeceiras do rio Carmo e seus afluentes, e próximo ao PERD. A Mata Atlântica residual é classificada como Floresta Estacional Semidecidual, 
ocupando cerca de 30\% da área, de acordo com o Plano de Ação de Recursos Hídricos da UPGRH DO1 (IGAM, 2010).

Quanto aos tipos de solo, o predomínio é de Latossolo VermelhoAmarelo e Latossolo Vermelho, mas destaca-se também, a classe do Argissolo que se encontra no centro da área, avançando na direção dos vales dos principais rios, e o Latossolo Amarelo na região do PERD e seu entorno. O Argissolo, encontrado no centro e em algumas manchas a sudeste do PERD, juntamente com uma mancha de Cambissolo também nessa região, constituem os solos eutróficos na UPGRH DO1, sendo as demais classes classificadas como solos distróficos (UFV et al. 2010).

O relevo (Figura 1) apresenta basicamente três domínios bem distintos: o domínio de baixas altitudes, que engloba a Depressão do Rio Doce e Planícies Fluviais; o domínio de médias altitudes, que se caracteriza pela presença de feições típicas do domínio dos mares de morro, correspondendo ao Planalto Centro-Sul Mineiro e Campos das Vertentes; e o terceiro domínio corresponde às áreas de maior elevação que circundam toda a UPGRH DO1, exceto no limite norte. A leste, são encontrados maciços elevados; a oeste, a Serra do Espinhaço e a borda sudeste do Quadrilátero Ferrífero (IBGE, 2010).

Em relação ao padrão climático observado na UPGRH DO1, é apropriado partir de um contexto mais amplo em virtude da natureza do fenômeno. O traço mais marcante do Sudeste brasileiro é a distribuição espacial e temporal da precipitação, que apresenta alta variação inter e intraanual. Essa variabilidade está associada aos controles de grande escala, aos distúrbios de mesoescala, à incursão de massas polares e da Zona de Convergência do Atlântico Sul (ZCAS), além de condições locais como topografia, exposição de vertentes e uso da terra (ALVES et al., 2005). Dentre os fenômenos de grande escala, os impactos de alguns deles, como os eventos de El Niño, La Niña e da Oscilação Decadal do Pacífico, são parcialmente conhecidos (IRACEMA et al., 2009).

A precipitação tem distribuição espacial com variações significativas por toda a extensão territorial de Minas Gerais, e uma distribuição temporal 
com duas estações bem definidas: a chuvosa, de outubro a março, e a seca, de abril a setembro (NUNES, VICENTE e CANDIDO, 2009). No caso da UPGRH DO1, a parte sul da área apresenta um padrão climático com três meses de seca, com variações na cabeceira, que apresenta um padrão superúmido com subseca; e na foz, com um clima semiúmido e quatro a cinco meses de seca. Considerando a bacia do rio Doce, as maiores médias pluviométricas registradas a montante são favorecidas pelas maiores altitudes. Essas áreas funcionam como zonas de condensação que fortalecem assim a atuação das chuvas convectivas e, associado às temperaturas mais baixas, permitem maior umidade nessas áreas em comparação com as áreas a jusante (CUPOLILLO, ABREU e VIANELLO, 2008).

\section{Materiais e Métodos}

Sobre os dados utilizados na implementação do SEBAL, foram aplicadas as seguintes padronizações cartográficas: i) Projeção Universal Transversa de Mercator (UTM) - Fuso 23 Sul e datum horizontal SIRGAS2000.

Os dados brutos de entrada são apresentados no esquema da Figura 2, na qual se pode observar o encadeamento geral do processamento do SEBAL visando à estimativa da evapotranspiração real horária e diária.

Figura 2 - Esquema geral das bases de dados necessárias à implementação do SEBAL.

\begin{tabular}{|c|c|c|}
\hline $\begin{array}{c}\text { Imagem de } \\
\text { Satélite }\end{array}$ & $\begin{array}{c}\text { Dados } \\
\text { Meteorológicos }\end{array}$ & $\begin{array}{c}\text { Modelo Digital } \\
\text { de Terreno }\end{array}$ \\
\hline $\begin{array}{c}\text { Saldo de } \\
\text { Radiação }\end{array}$ & $\begin{array}{c}\text { Fluxo de Calor } \\
\text { do Solo }\end{array}$ & $\begin{array}{c}\text { Fluxo de Calor } \\
\text { Sensível }\end{array}$ \\
& $\begin{array}{c}\text { Fluxo de Calor } \\
\text { Latente }\end{array}$ \\
& $\begin{array}{c}\text { Evapotranspiração } \\
\text { Real horária e Diária }\end{array}$ \\
\hline
\end{tabular}

Fonte: Elaborado pelos autores, com base em Allen, Tasumi e Trezza (2002). 
No presente estudo, foram utilizadas imagens do Landsat 8 - bandas $2,3,4,5,6$ e 7 para a estimativa do albedo da superfície $(\alpha)$; bandas 4 e 5 para estimativa dos índices de vegetação; e banda 10 para a estimativa da temperatura da superfície $\left(T_{S}\right)$. Para cobrir a área de estudo são necessárias imagens referentes a duas cenas: órbitas/pontos 217-74 e 217-75. Essas imagens são de 25 de setembro de 2015, as quais foram escolhidas em função da ausência de cobertura de nuvens, requisito necessário à aplicação do algoritmo.

Os dados meteorológicos para estimativa da evapotranspiração com o SEBAL são: velocidade do vento; precipitação; umidade relativa, pressão de vapor ou temperatura do ponto de orvalho; radiação solar e temperatura do ar. Para a execução do SEBAL, usaram-se os dados da estação Timóteo, apresentada na Tabela 1, juntamente com as demais estações utilizadas para validação. Os dados correspondem a medições horárias e foram fornecidos pelo convênio de cooperação técnica entre o INMET e a Universidade Federal de Minas Gerais - UFMG D05/081/2008.

Tabela 1 - Estações automáticas do INMET.

\begin{tabular}{l|c|c|c}
\hline \multicolumn{1}{c|}{ Estação } & Latitude* & Longitude* & $\begin{array}{c}\text { Altitude } \\
\text { (metros) }\end{array}$ \\
\hline Barbacena-A502 & $-21,23$ & $-43,77$ & 1169 \\
\hline Caratinga-A554 & $-19,74$ & $-42,14$ & 609 \\
\hline Timóteo-A511T & $-19,57$ & $-42,62$ & 493 \\
\hline Viçosa-A510 & $-20,76$ & $-42,86$ & 698 \\
\hline
\end{tabular}

* Datum: SIRGAS2000

Fonte: Elaborado pelos autores a partir de dados do INMET.

Os dados numéricos do relevo brasileiro são disponibilizados pela Empresa Brasileira de Pesquisa Agropecuária (EMBRAPA) por meio do projeto Brasil em Relevo (MIRANDA, 2005). A fonte primária dos dados tem como origem a missão do ônibus espacial de topografia por radar - Shuttle Radar Topography Mission (SRTM), um projeto desenvolvido pela National Aeronauticsand Space Administration (NASA) e National Geospatial Intelligence Agency (NGA) dos Estados Unidos em 2000. A utilização desses 
dados do relevo tem como objetivo melhorar a estimativa dos parâmetros do balanço de energia para área de relevo acidentado.

Todos os processamentos foram executados considerando a extensão das imagens de satélite, sendo os resultados recortados para a área de interesse, UPGRH DO1.

\subsection{Transformações Geométricas e Radiométricas}

Quanto às transformações geométricas não foi efetuado nenhum processamento nas imagens Landsat 8, adotando-se assim o nível de correção oferecido pelo produto disponibilizado pelo United States Geological Survey (USGS). Quanto às correções radiométricas, considerando que as imagens são disponibilizadas na forma de números digitais (ND), foi necessária a conversão para valores físicos de radiância e reflectância.

Originalmente no SEBAL, a correção realizada era apenas para reflectância no topo da atmosfera. Neste estudo, utilizou-se a correção para a reflectância de superfície $\left(\rho_{s}\right)$, dado disponibilizado sob demanda, no site do USGS <http://earthexplorer.usgs.gov/>. Esse dado é utilizado para o cálculo do albedo da superfície $(\alpha)$ e dos índices de vegetação.

A reflectância de superfície constitui um produto de nível 2 (alto nível) com correção atmosférica utilizando o algoritmo Landsat 8 Surface Reflectance Code - LaSRC (USGS, 2016; VERMOTE et al., 2016), específico para o Landsat 8. Assim foi necessário o cáculo apenas da radiância espectral $\left(L_{\lambda}\right)$ para a banda 10, utilizando a Equação 2, apresentada em USGS (2015a) - dado utilizado para a estimativa da temperatura da superfície $\left(T_{s}\right)$ :

$$
L_{\lambda}=M_{L} \cdot Q_{c a l}+A_{L}
$$

em que, $M_{L}$ é o fator de escala de radiância multiplicativo por banda; $A_{L}$ é o fator de escala de radiância aditivo por banda; $Q_{c a l}$ é o valor do ND do pixel. 
Também foram realizados os seguintes procedimentos adicionais nas bandas espectrais: i) multiplicação dos valores de reflectância de superfície pelo fator de escala $(0,0001)$, o que é necessário para se obter os valores reais (USGS, 2015b); ii) mosaicagem de cada banda espectral das cenas, órbitas/pontos 217-74 e 217-75.

\subsection{Estimativa do Fluxo de Calor Latente}

Sobre essa estimativa, têm-se as seguintes observações: i) foram realizados dois modelos: Modelo 1 - sem correção para a influência do relevo; Modelo 2 - com correção para a influência do relevo; ii) os dados meteorológicos utilizados na estimativa de $\lambda E T$ correspondem às 13:00 UTC, hora mais próxima do momento de aquisição da imagem, 12:51 GMT (=UTC); iii) a maioria das equações utilizadas nessa seção e nas seguintes são descritas em Allen, Tasumi e Trezza (2002); sendo apresentadas aqui apenas as equações principais, e são indicados os parâmetros que passam por correção para assimilar a influência do relevo. Para as equações de outras fontes, são indicadas as referências correspondentes ao apresentá-las.

Para a estimativa do fluxo de calor latente são calculados o saldo de radiação na superfície terrestre $\left(R_{n}\right)$, o fluxo de calor no solo $(G)$ e o fluxo de calor sensível no ar $(H)$.

\subsubsection{Saldo de Radiação na Superfície Terrestre}

$\mathrm{O}$ saldo de radiação na superfície terrestre $\left(R_{n} W \mathrm{~m}^{-2}\right)$ corresponde à energia radiante disponível, considerando todos os fluxos de energia incidentes na superfície (entrada) e emitidos pela superfície (saída). Esse cálculo é realizado utilizando a Equação 3 e a sequência dos processamentos executados, bem como dos principais parâmetros necessários à sua estimativa, são apresentados no fluxograma da Figura 3, considerando o modelo para relevo plano: 


$$
R_{n}=(1-\alpha) R_{S \downarrow}+R_{L \downarrow}-R_{L \uparrow}-\left(1-\varepsilon_{0}\right) R_{L \downarrow}
$$

em que, $\alpha$ é o albedo da superfície (adimensional); $R_{S \downarrow}$ é a radiação de onda curta incidente $\left(W \mathrm{~m}^{-2}\right) ; R_{L \downarrow}$ é a radiação de onda longa incidente $\left(W m^{-2}\right) ; R_{L \uparrow}$ é a radiação de onda longa emitida $\left(W m^{-2}\right) ; \varepsilon_{0}$ é a emissividade da superfície (adimensional).

O albedo da superfície $(\alpha)$ é calculado a partir da equação apresentada em Tasumi, Allen e Trezza (2008), proposta em substituição à forma tradicional presente em Allen, Tasumi e Trezza (2002). Para a aplicação dessa equação, utizaram-se coeficientes desenvolvidos para o Landsat 7, devido à inexistência (na bibliografia consultada) de coeficientes estimados para o sensor Operacional Terra Imager (OLI.)

Em relação ao $R_{n}$, a correção para a influência do relevo ocorre nos parâmetros $R_{S \downarrow}$, considerando a declinação da Terra $(\delta)$, a latitude do pixel $(\varphi)$, a declividade $(s)$, a orientação das vertentes $(\gamma)$ e o ângulo horário $(\omega)$; e $R_{L \downarrow}$, utilizando a altitude do pixel.

Figura 3 - Fluxograma da estimativa do saldo de radiação na superfície terrestre, considerando o modelo sem correção para a influência do relevo.

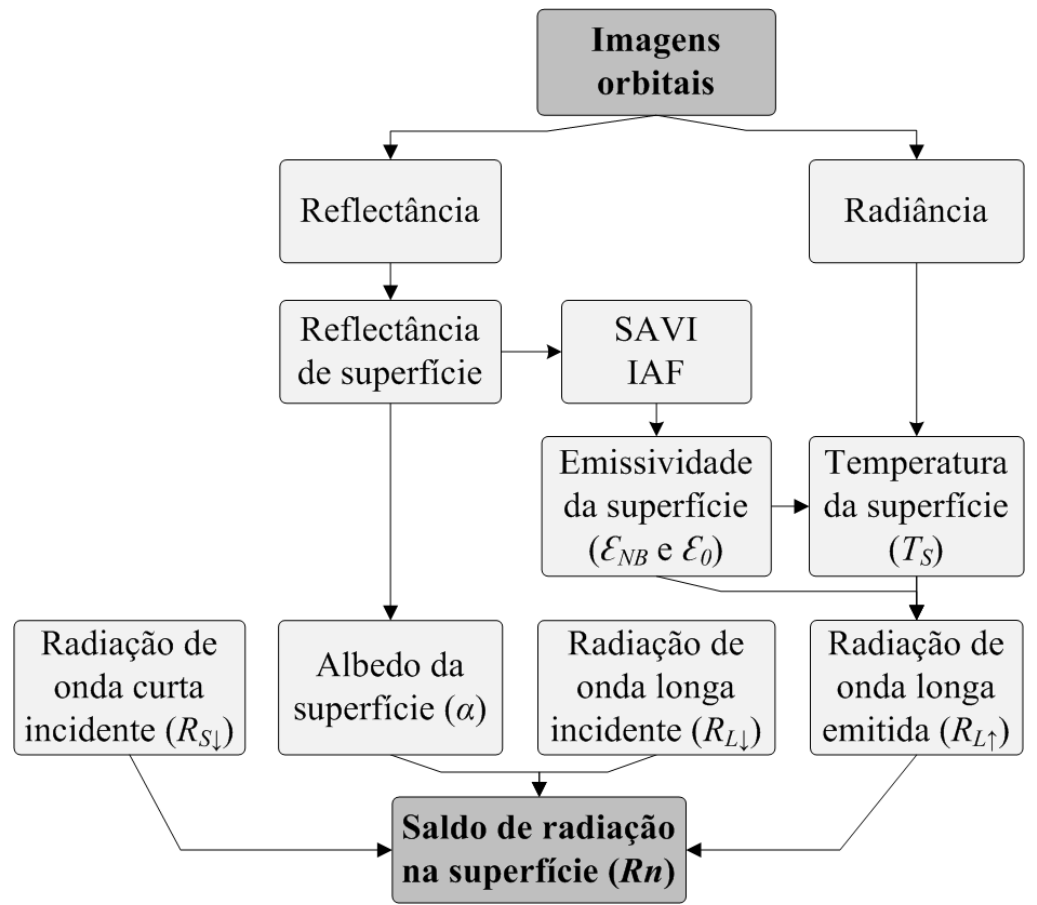

Fonte: Modificado de Allen, Tasumi e Trezza (2002). 


\subsubsection{Fluxo de Calor no Solo}

O fluxo de calor no solo $(G)$ corresponde à energia utilizada para a mudança de temperatura do solo, sendo positivo quando o solo está aquecendo e negativo quando está esfriando. Sua dimensão é pequena quando comparado com o saldo de radiação $\left(R_{n}\right)$, podendo ser ignorado para estimativas diárias, porém para valores horários, recomenda-se que seja considerado (ALLEN et al., 1998). No caso do SEBAL, para o cálculo de $G$, inicialmente, aplica-se a razão empírica $G / R_{n}$, apresentada na Equação 4, desenvolvida por Bastiaanssen (2000); em seguida, multiplica-se $G / R_{n}$ por $R_{n}$ para a obtenção de $G\left(W m^{-2}\right)$ :

$$
\frac{G}{R_{n}}=T_{s}(0,0038+0,0074 \alpha)\left(1-0,98 N D V I^{4}\right)
$$

em que, $T_{S}$ é a temperatura da superfície $\left({ }^{\circ} \mathrm{C}\right) ; \alpha$ é o albedo da superfície (adimensional); NDVI é o índice de vegetação por diferença normalizada.

Para corpos d'água, a estimativa de $G$ é complexa, sofrendo variações devido à profundidade e à presença de sedimentos. Allen, Tasumi e Trezza (2002) indicam o uso de 0,5 para a razão $G / R_{n}$ em corpos d'água profundos e claros, em casos opostos, o valor tende a ser menor. Neste estudo, adotou-se o valor de 0,3; utilizado por Nicácio (2008).

\subsubsection{Fluxo de Calor Sensível}

O fluxo de calor sensível $\left(H W m^{-2}\right)$ é dado em função do gradiente vertical de temperatura próximo à superfície da Terra e uma dada altura sobrejacente; da rugosidade do terreno e da velocidade do vento, constituindo a parte mais sensível do cálculo no SEBAL. Esse parâmetro não pode ser estimado diretamente a partir dos dados orbitais, sendo calculado a partir da

Equação 5, considerando relações indiretas com produtos de imagens de satélite e a utilização de dados da estação meteorológica: 


$$
H=\rho_{a r} \cdot C_{p} \cdot \frac{d T}{r_{a h}}
$$

em que, $\rho_{a r}$ é a densidade do ar $\left(1,15 \mathrm{~kg} \mathrm{~m}^{-3}\right)$; $c_{p}$ é o calor específico do

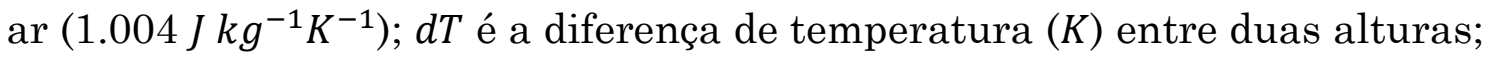
$r_{a h}$ é a resistência aerodinâmica ao transporte de calor $\left(\mathrm{s} \mathrm{m}^{-1}\right)$.

Inicialmente, calcula-se $H$ para condições neutras da atmosfera, situação na qual os movimentos verticais ascendentes não estão ocorrendo e não estão sendo inibidos (PEREIRA, SEDIYAMA e VILLA NOVA, 2013). Após essa primeira estimativa, deve-se realizar um processo iterativo para correção dos fatores $r_{a h}, \rho_{a r}, d T$ e, consequentemente, de $H$ (Figura 4).

Figura 4 - Sequência de processos para o cálculo do fluxo de calor sensível (H) - as setas contínuas indicam a primeira estimativa, e as tracejadas, o processo iterativo.

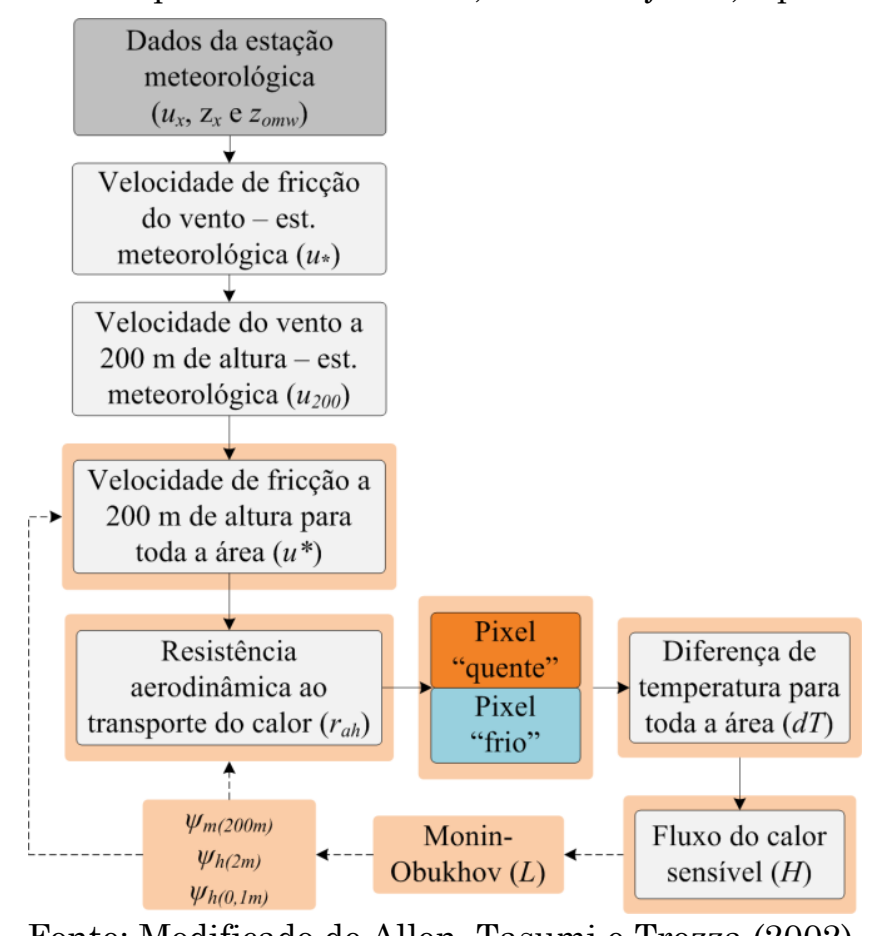

Fonte: Modificado de Allen, Tasumi e Trezza (2002).

A resistência aerodinâmica ao transporte de calor $\left(r_{a h} s m^{-1}\right)$ varia em função da razão entre duas alturas, da rugosidade do terreno (altura da vegetação) e do inverso da velocidade de fricção do vento (PEREIRA, SEDIYAMA e VILLA NOVA, 2013), sendo computada inicialmente pela Equação 6, considerando a atmosfera neutra: 


$$
r_{a h}=\frac{\ln \left(z_{2} / z_{1}\right)}{u^{*} \cdot k}
$$

em que, $z_{1}$ e $z_{2}$ são iguais à altura em metros acima do plano zero de deslocamento da vegetação; $u^{*}$ é a velocidade de fricção $\left(s m^{-1}\right) ; k$ é a constante de von-Karman (0,41). Para $z_{1}$ e $z_{2}$, Allen, Tasumi e Trezza (2002) indicam os valores de 0,1 e $2,0 \mathrm{~m}$, respectivamente.

A velocidade de fricção do vento $\left(u^{*} s m^{-1}\right)$ para toda a área é estimada pela Equação 7, sendo derivada a partir da velocidade do vento na estação meteorológica:

$$
u^{*}=\frac{k \cdot u_{200}}{\ln \left(z_{200} / z_{o m}\right)}
$$

em que, $u_{200}$ é a velocidade do vento à altura de $200 \mathrm{~m}$ na estação meteorológica $\left(s \mathrm{~m}^{-1}\right) ; z_{200}$ é a "altura de mistura", aqui considerada $200 \mathrm{~m}$, seguindo indicação de Allen, Tasumi e Trezza (2002); $z_{o m}$ é o coeficiente de rugosidade da superfície para toda a área. A altura de mistura é considerada a altura em que não há mais influência da rugosidade do terreno na velocidade do vento.

O coeficiente de rugosidade da superfície $\left(z_{o m}\right)$ para toda a extensão da área pode ser derivado a partir de relações empíricas com índices de vegetação. Neste estudo, utiliza-se a Equação 8, modificada a partir de Bastiaanssen (2000):

$$
z_{o m}=\exp (a N D V I+b)
$$

em que, $a$ e $b$ são coeficientes regressivos ( $a=3,157$ e $b=-2,818)$. Adotaram-se os coeficientes utilizados por Ruhoff (2011) na bacia hidrográfica do rio Grande, localizada na divisa de São Paulo e Minas Gerais.

No cálculo de $(H)$, a correção para a influência do relevo ocorre nos parâmetros $z_{o m}$, utilizando a declividade $(s)$ e em $u_{200}$ utilizando um coeficiente de ponderação definido em função da altitude na estação 
meteorológica e da altitude em cada pixel, ambas apresentadas por Allen, Tasumi e Trezza (2002, 2007).

\subsubsection{Determinação da Função $d T$}

A diferença de temperatura entre duas alturas (dT) assume uma relação linear entre $d T$ e a temperatura da superfície terrestre $\left(T_{s}\right)$, dada pela Equação 9, proposta por Bastiaanssen (1995):

$$
d T=b+a T_{s}
$$

em que, a e b são coeficientes regressivos. Para o cálculo desses coeficientes, o SEBAL faz uso de pixels "âncoras" (pixel "frio" e "quente") Figura 4, que foram selecionados para a área de interesse conforme orientações de Allen, Tasumi e Trezza (2002). A ideia é que eles representem condições extremas de temperatura na área em estudo. Para esses pixels é possível calcular o valor de $H$ com segurança e, assim, $d T$ pode ser estimada para cada pixel "âncora" pela Equação 10:

$$
d T_{x}=\frac{H_{x} \cdot r_{a h_{x}}}{\rho_{a r_{x}} \cdot c_{p}}
$$

em que, x corresponde ao pixel "frio" ou "quente".

A $r_{a h}$ já foi calculada - Equação $6 ; H_{\text {frio }}=R_{n}-G-\lambda E T_{\text {frio }}$ e $H_{\text {Quente }}=$ $R_{n}-G-\lambda E T_{\text {Quente }}$, em que, $R_{n}$ e $G$ são valores estimados pelas Equações 3 e 4, respectivamente; e para $\lambda E T_{\text {Quente }}$, assume-se que seja 0 . Para essa suposição, é necessário que não tenha ocorrido chuva nos 4-5 dias anteriores à aquisição da imagem, condição atestada em todas as estações apresentadas na Tabela 1. Já em relação ao $\lambda E T_{\text {frio }}$, considera-se que a $E T_{\text {frio }}$ seja $5 \%$ maior que a $E T_{0}$, valor de referência para a alfafa em situação de solo sem deficiência hídrica, característica do pixel escolhido. Assim, para o cálculo de $\lambda E T_{\text {frio }}$, aplicou-se a Equação 14. 
Conhecendo-se a diferença de temperatura $(d T)$ e a temperatura de superfície dos pixels "âncoras" foi possível calcular os coeficientes regressivos e, assim, determinar $d T$ para toda a área de estudo.

\subsubsection{Processo Iterativo de Correção para a Estabilidade Atmosférica}

No primeiro momento, a resistência aerodinâmica ao transporte de calor $\left(r_{a h}\right)$ - Equação 6, é estimada para condições neutras da atmosfera, gerando um valor para o fluxo de calor sensível $(H)$ incorreto. A correção da $r_{a h}$ considera a aplicação da teoria de similaridade de Monin-Obukhov ( $L$ ) que é uma função do momentum e transporte de calor. Primeiro, calcula-se $L$ pela Equação 11:

$$
L=\frac{\rho_{a r} \cdot C_{p} \cdot\left(u^{*}\right)^{3} \cdot T_{S}}{K \cdot g \cdot H}
$$

em que, $g$ é a aceleração gravitacional $\left(9,81 \mathrm{~m} \mathrm{~s}^{-2}\right) . L<0$ indica condições instáveis da atmosfera; $L>0$ indica condições estáveis, e $L=0$ indica condições neutras. De acordo com cada condição, se aplica as formulações matemáticas de Paulson (1970) e Webb (1970) apresentadas em Allen, Tasumi e Trezza (2002), para o cálculo do momentum e transporte de calor $\left(\psi_{m}\right.$ e $\left.\psi_{h}\right)$.

A partir dos valores de $\psi_{m}$ e $\psi_{h}$ calcula-se novamente $u^{*}$ e $r_{a h}$ corrigidas, por meio das Equações 12 e 13:

$$
\begin{gathered}
u^{*}=\frac{k \cdot u_{200}}{\ln \left(z_{200} / z_{o m}\right)-\psi_{m(200 m)}} \\
r_{a h}=\frac{\ln \left(z_{2} / z_{1}\right)-\psi_{h\left(z_{2)}\right.}+\psi_{h\left(z_{1}\right)}}{u^{*} \cdot k}
\end{gathered}
$$

Com o valor da $r_{a h}$ corrigido, gera-se novamente a função $d T$, com novos coeficientes, que são utilizados para calcular um novo $d T$ para os pixels âncoras, repetindo-se o processo (Figura 4) até ocorrer a estabilização dos 
valores de $d T$ e da $r_{a h}$ para o pixel "quente" (ALLEN, TASUMI e TREZZA, 2002).

\subsection{Evapotranspiração Real Horária e Diária}

A partir da aplicação da Equação 1, que calcula o fluxo de calor latente ( $\lambda E T)$ como um resíduo do balanço de energia, a evapotranspiração real horária $\left(E T_{h} m m h^{-1}\right)$ é estimada utilizando-se a Equação 14:

$$
E T_{h}=3.600 \frac{\lambda E T}{\lambda}
$$

em que, 3.600 corresponde à conversão de 1 hora para segundos; $\lambda$ é o calor latente de vaporização $\left(\mathrm{kg}^{-1}\right)$ - estimado de acordo com Allen, Tasumi e Trezza (2007).

Para a extrapolação da $E T_{h}$ para evapotranspiração real diária $\left(E T_{24 h} \mathrm{~mm} \mathrm{~d}^{-1}\right)$ ao longo de toda a área, utiliza-se a Equação 15:

$$
E T_{24 h}=E T_{0} F \cdot E T_{0_{24 h}}
$$

em que, $E T_{0} F$ é a fração da evapotranspiração de referência (adimensional); $E T_{0_{24 h}}$ é a evapotranspiração de referência diária da estação meteorológica para o mesmo dia de aquisição da imagem.

A fração $E T_{0} F\left(E T_{h} / E T_{0_{-} h}\right)$ permanece praticamente constante durante o dia e, dessa forma, permite uma boa aproximação para a estimativa da $E T_{24 h}$ (ALLEN, TASUMI e TREZZA, 2002). ET $T_{0 \_}$, nesse caso, corresponde à evapotranspiração de referência horária.

2.4 Cobertura e Uso da Terra versus Evapotranspiração Real Diária

Com o objetivo de se fazer uma relação geral da média de contribuição de vapor d'água diário para a atmosfera e os tipos de cobertura e uso da terra, 
foram mapeadas quatro classes, utilizando-se as bandas do espectro visível: Esse mapeamento foi realizado por classificação não supervisionada (MATHER, 2004) e os corpos d'água foram corrigidos, considerando o SoilAdjusted Vegetation Index - SAVI (PROFETA, 2017).

Foram mapeadas as classes: Água: corpos d'água mapeáveis considerando a resolução espacial da imagem; Floresta - Silvicultura: áreas com fragmentos de Mata Atlântica e práticas de silvicultura, principalmente o eucalipto; Vegetação herbácea: áreas onde predomina o uso agropecuário; e Áreas não vegetadas: áreas de solo exposto onde se encontra a prática da agricultura, áreas em topos de morro e vertentes com vegetação rarefeita e sob efeito do estresse hídrico, mais áreas urbanas.

\section{Resultados e Discussões}

A aplicação do SEBAL permitiu a estimativa da evapotranspiração horária com a solução da Equação 14, a partir do fluxo de calor latente ( $\lambda E T)$. A evapotranspiração diária foi estimada considerando a fração da evapotranspiração de referência, que de acordo com Allen, Tasumi e Trezza (2002), é similar ao coeficiente de cultura $\left(K_{c}\right)$. Os valores obtidos para os Modelos 1 e 2 são apresentados nos mapas das Figuras 5 e 6, com resolução espacial de $30 \mathrm{~m}$.

Nos dois modelos considerados, observa-se um comportamento influenciado principalmente pela vegetação, na qual a evapotranspiração é maior quanto maior o índice de vegetação que recobre a superfície da área. Essa influência foi também evidenciada em outras variáveis, como albedo da superfície $(\alpha)$, temperatura da superfície $\left(T_{S}\right)$ e fluxo de calor no solo $(G)$. É possível, assim, perceber uma contribuição maior de vapor d'água para a atmosfera na parte oeste da área de estudo, enquanto a parte leste, com exceção do PERD, possui uma contribuição restrita, que tende a zero nas áreas não vegetadas. As médias obtidas para os Modelos 1 e 2 foram, 
respectivamente, 0,44 e 0,42 $\mathrm{mm}^{-1}$, para a evapotranspiração real horária; e 4,95 e 4,74 $\mathrm{mmd}^{-1}$, para a evapotranspiração real diária.

Figura 5 - Mapas dos valores da evapotranspiração real horária estimados para a UPGRH DO1 em 25/09/2015: (a) Modelo 1; (b) Modelo 2.

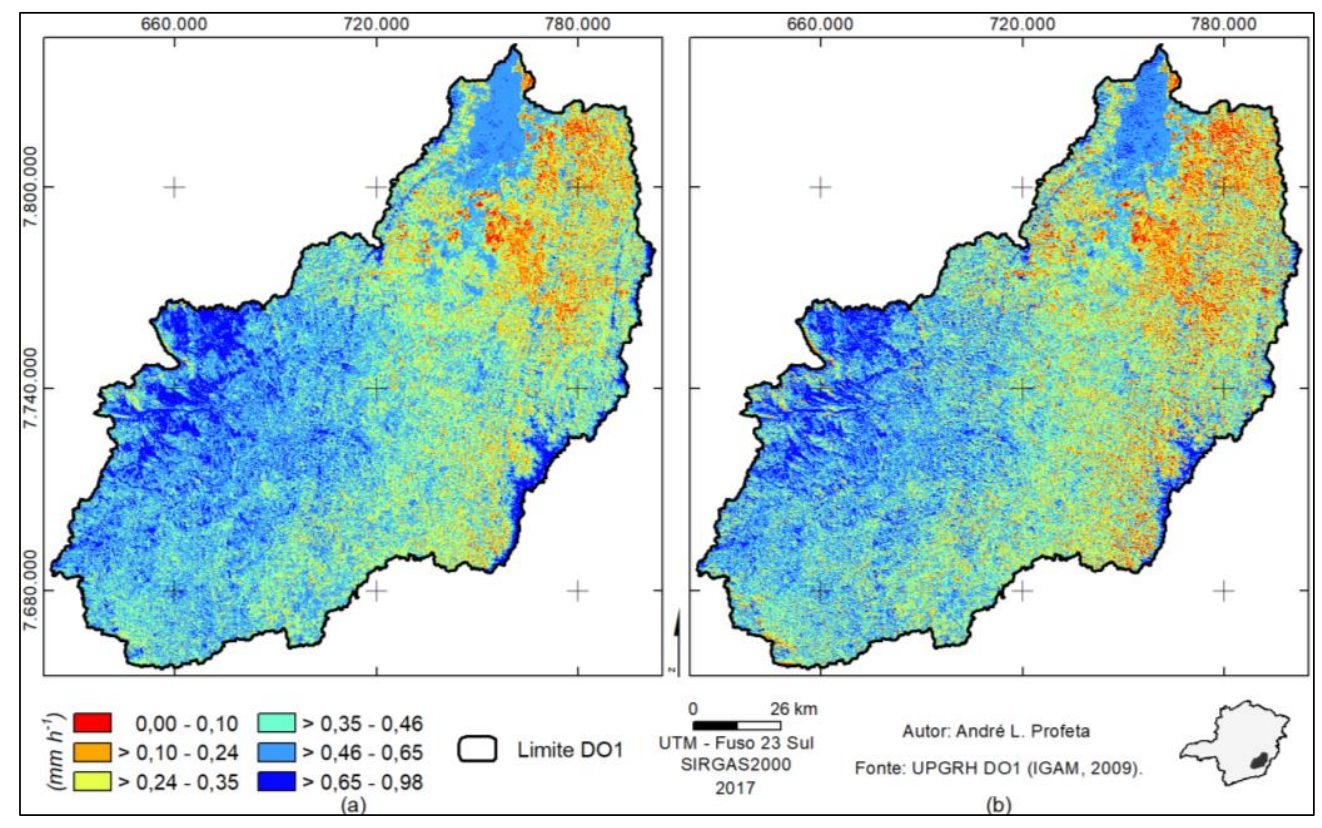

Fonte: Elaborada pelos autores.

Figura 6 - Mapas dos valores da evapotranspiração real diária estimados para a UPGRH DO1 em 25/09/2015: (a) Modelo 1; (b) Modelo 2.

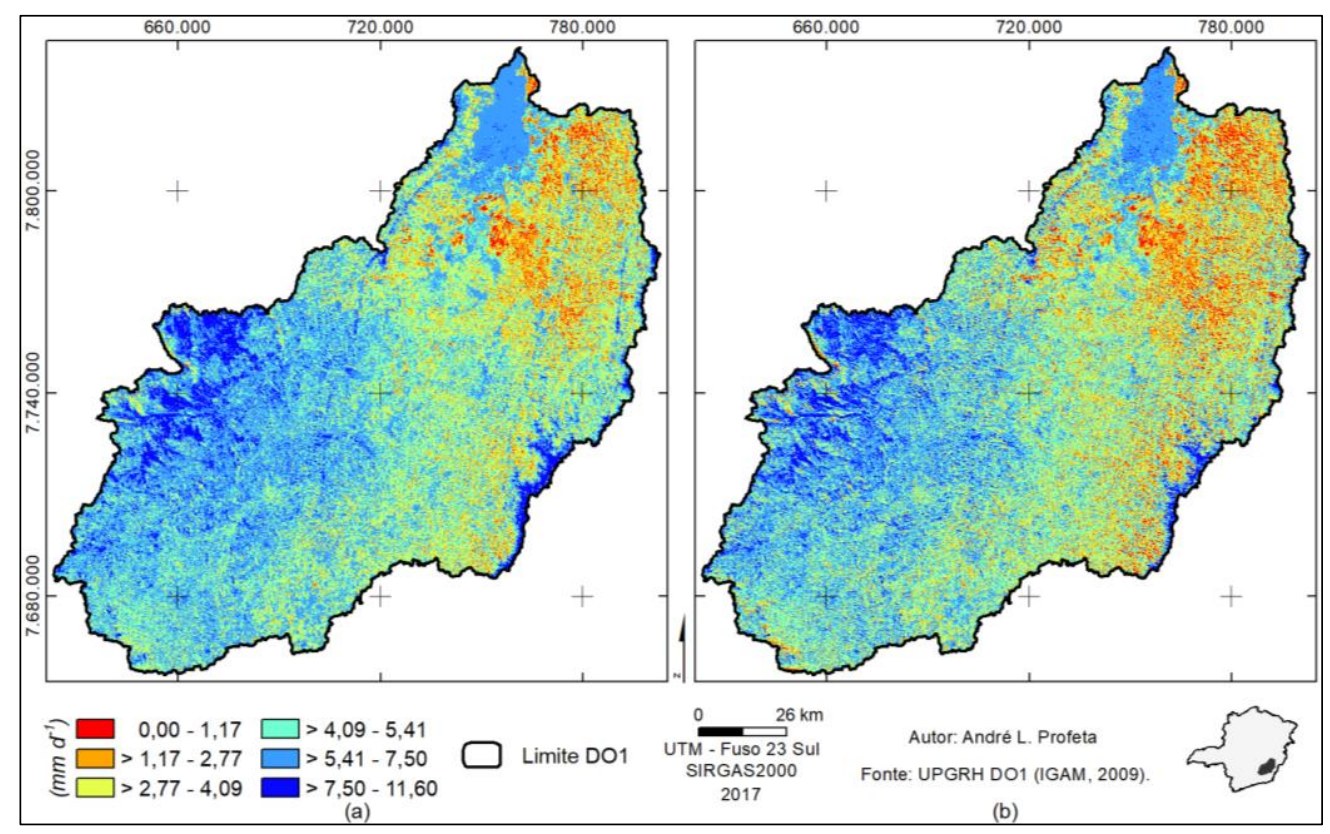

Fonte: Elaborada pelos autores. 
A Figura 7 apresenta o mapa de cobertura e uso da terra na UPGRH DO1. Esse mapeamento permite uma associação entre a evapotranspiração real e os tipos de vegetação (quanto ao porte) e presença/ausência de vegetação.

Figura 7 - Mapa de cobertura e uso da terra na UPGRH DO1 em 25/09/2015.

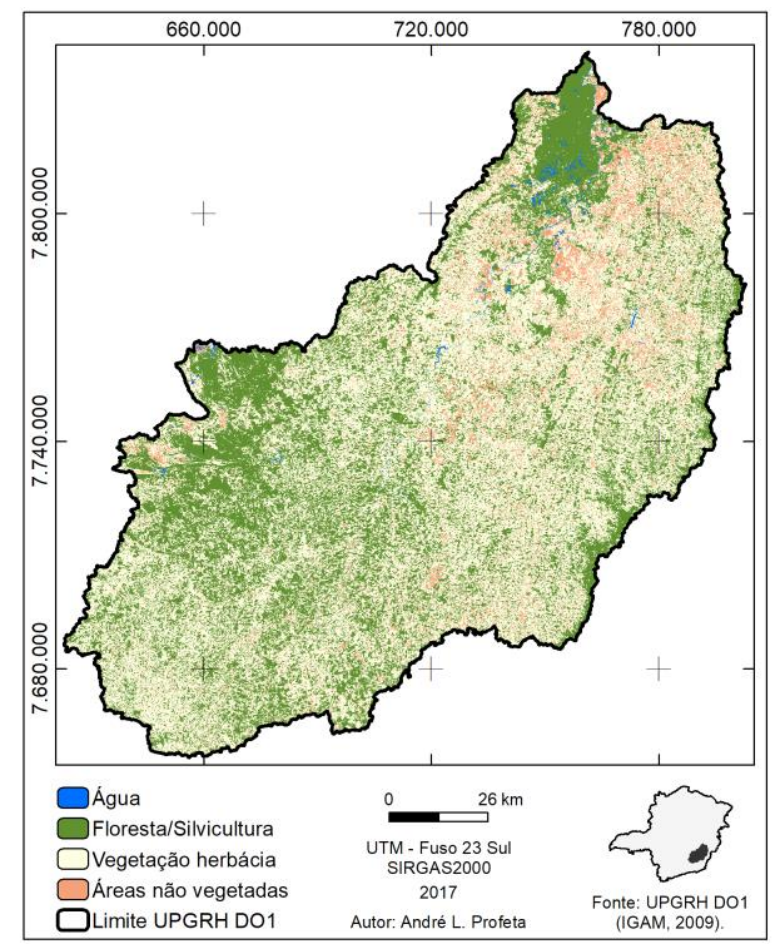

Fonte: Elaborada pelos autores.

As contribuições médias de vapor d'água para a atmosfera das classes mapeadas são apresentadas na Tabela 2, de acordo com cada modelo. Os valores evidenciam a associação entre o porte da vegetação (ou ausência) e os valores de evapotranspiração real diária. Assim, verifica-se em áreas de floresta ou silvicultura, uma contribuição média de 6,45 e 6,02 mm $\mathrm{mm}^{-1}$ para os Modelos 1 e 2, respectivamente, enquanto que em áreas não vegetadas, têm-se 2,54 e $2,26 m m d^{-1}$.

De acordo com esses resultados, o Modelo 2, com exceção da classe 'Água', apresenta sempre menores valores de evapotranspiração e um desvio padrão maior em cada classe, quando comparado ao Modelo 1. De fato, esse 
resultado é esperado, pois ao considerar as variações de relevo, espera-se maior variância dos dados.

Tabela 2 - Valores diários de evapotranspiração média de acordo a cobertura e uso da terra, $-25 / 09 / 2015$

\begin{tabular}{|c|c|c|c|c|c|}
\hline \multirow[b]{2}{*}{ Classes } & \multirow{2}{*}{$\begin{array}{l}\text { Área } \\
\left(\mathrm{km}^{2}\right)\end{array}$} & \multicolumn{2}{|c|}{ Modelo 1} & \multicolumn{2}{|c|}{ Modelo 2} \\
\hline & & $\begin{array}{c}E T_{24 h} \\
\left(m m^{-1}\right)\end{array}$ & DP* & $\begin{array}{c}E T_{24 h} \\
\left(m m^{-1}\right)\end{array}$ & DP* \\
\hline Água & 65 & 6,52 & 0,9 & 6,66 & 0,98 \\
\hline Floresta/Silvicultura & 6.527 & 6,45 & 1,04 & 6,02 & 1,4 \\
\hline Vegetação herbácea & 9.505 & 4,29 & 1,16 & 4,02 & 1,42 \\
\hline Áreas não vegetadas & 1.474 & 2,54 & 1,29 & 2,26 & 1,46 \\
\hline Área Total & 17.571 & 4,95 & 1,67 & 4,74 & 1,79 \\
\hline
\end{tabular}

Fonte: Elaborado pelos autores.

Para melhor compreender a relação entre o tipo de cobertura e uso da terra com os valores de evapotranspiração, apresenta-se um recorte do mapa de evapotranspiração real diária da Figura 6a em uma escala ampliada na parte sul do PERD, onde se verifica maior diversidade de cenários, juntamente com o mesmo recorte da imagem de satélite, em cores naturais (Figura 8). Analisando esse recorte, é possível estabelecer associações entre os baixos valores de evapotranspiração real diária com as regiões não vegetadas, bem como dos valores correspondentes às variações da vegetação. 
Figura 8 - a) Recorte do mapa de evapotranspiração real diária da Figura $6 \mathrm{a}$ - parte sul do PERD; b) Composição RGB432 do recorte da cena 217/74 da imagem Landsat 8 de 25/09/2015, correspondente a área do recorte em (a).

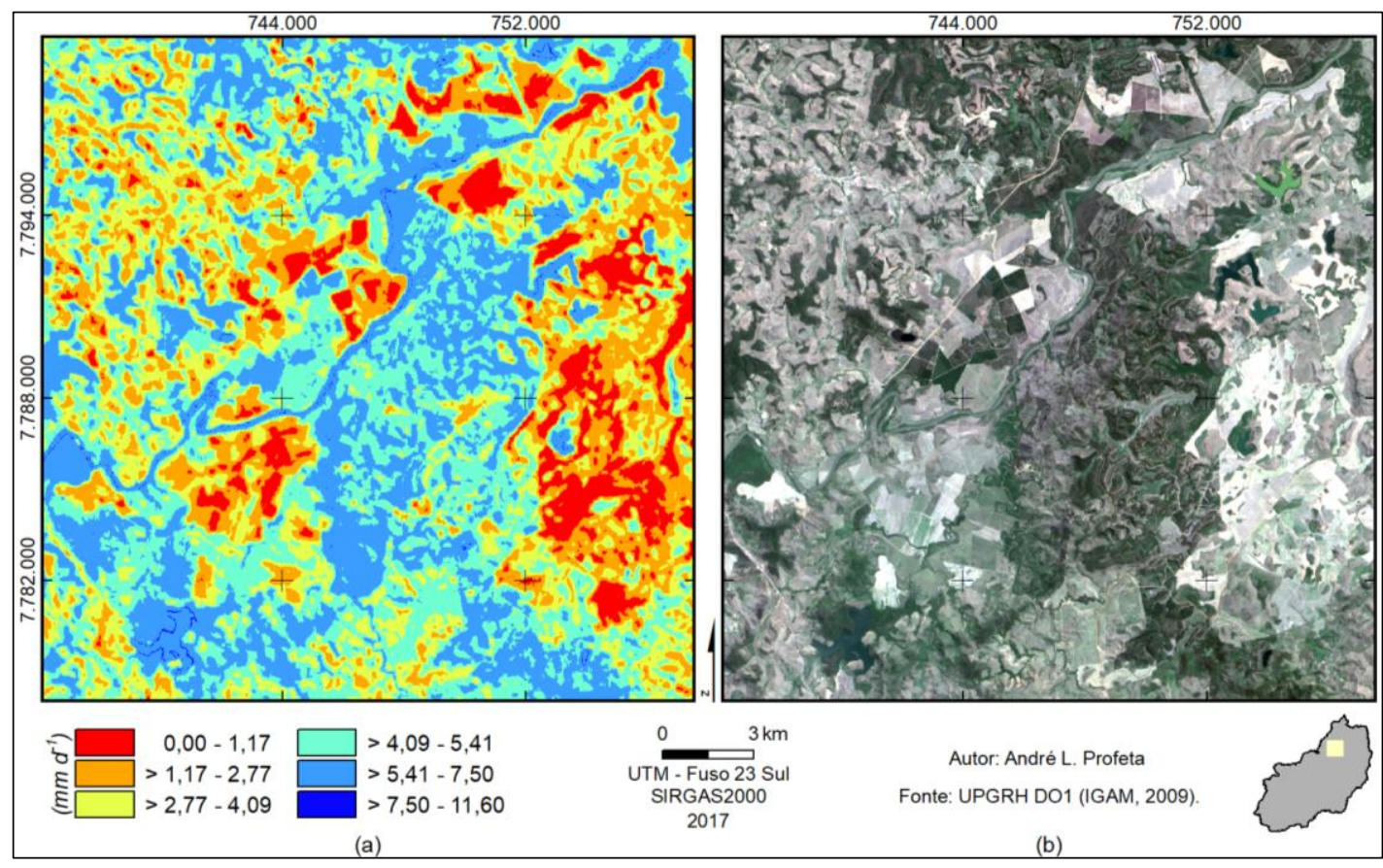

Fonte: Elaborada pelos autores.

\subsection{Avaliação dos resultados}

$\mathrm{Na}$ avaliação dos resultados, a título de comparação, utilizaram-se dados de estações automáticas do INMET (a localização das estações é apresentada na Tabela 1), com a estimativa da evapotranspiração de referência $\left(E T_{0}\right)$, processo realizado em outros estudos como em Boratto (2012) e Menezes (2006). Para isso, adotou-se o método Penman-Monteith - padrão FAO, utilizado para validar outros métodos de estimativa, conforme cita Pereira, Sediyama e Villa Nova (2013).

Na Figura 9, é apresentado um gráfico comparativo dos valores obtidos para a evapotranspiração de referência $\left(E T_{0}\right)$ horária, pelo método PenmanMonteith com os valores da evapotranspiração real horária, estimados pelo SEBAL - Modelos 1 e 2, nos pixels coincidentes com a localização das quatro estações consideradas. Na Figura 10 é apresentada a comparação para os valores da $E T_{0}$ diária. 
Para essa comparação, deve-se considerar que a $E T_{0}$ corresponde à evapotranspiração máxima de uma superfície de referência que depende apenas de condições atmosféricas e, segundo Pereira, Sediyama e Villa Nova (2013), se equipara à evapotranspiração potencial (ETP). Assim, admite-se que valores abaixo da $E T_{0}$ são esperados, situação verificada nas quatro estações.

Figura 9 - Comparação da $E T_{0}$ horária estimada pelo método Penman-Monteith - padrão FAO com a evapotranspiração real horária estimada pelo SEBAL - Modelos 1 e 2.

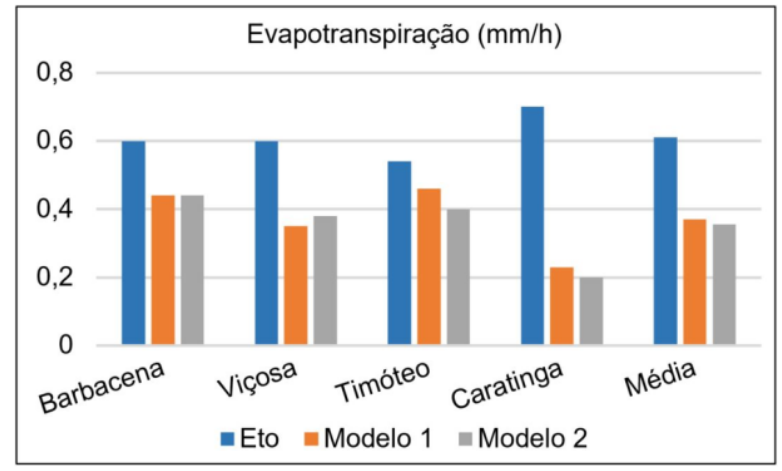

Fonte: Elaborado pelos autores.

Figura 10 - Comparação da $E T_{\mathbf{0}}$ diária estimada pelo método Penman-Monteith - padrão FAO com a evapotranspiração real diária estimada pelo SEBAL - Modelos 1 e 2.

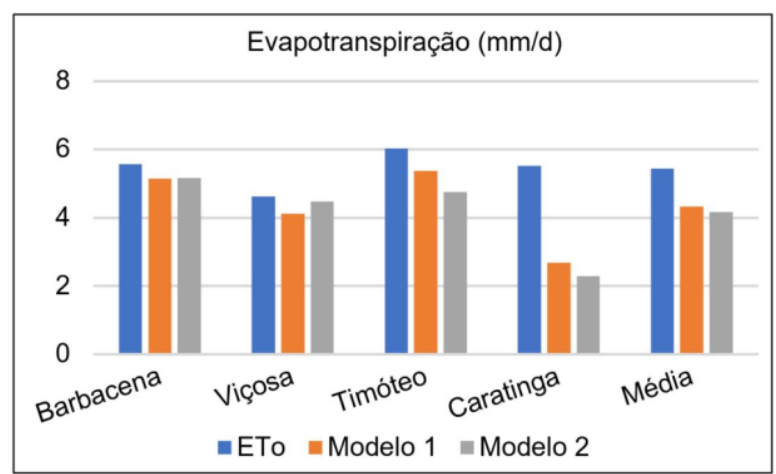

Fonte: Elaborado pelos autores.

Dessas estações, a situação mais discrepante se refere à estação Caratinga, entretanto, ao se analisar a localização dessa estação pode se dizer que, em termos de evapotranspiração real, os valores estimados são coerentes. Essa estação se localiza num topo de morro com vegetação rasteira, situação próxima das condições utilizadas para a escolha do pixel "quente" (Item 2.2.3.1). De fato, a temperatura da superfície de $308 \mathrm{~K}$ nesse pixel é acima da 
média de $304 \mathrm{~K}$ para a área em estudo e acima da temperatura verificada nas demais estações.

Em relação às estações Barbacena e Viçosa, principalmente quanto à evapotranspiração diária, observa-se uma aproximação com os valores estimados pelos dois modelos. Apesar disso, tem-se a seguinte observação: as duas estações se localizam muito próximas a áreas urbanas, podendo sofrer influências tanto nos dados meteorológicos, como nos dados de sensoriamento remoto.

A estação Timóteo se encontra em uma área com maior presença de vegetação e menor influência urbana e, devido a essas condições, foi adotada para fornecer os parâmetros requeridos na execução do SEBAL.

Com base nessa comparação, verifica-se que os valores estimados pelos Modelo 1 e 2 são próximos e, em média, o Modelo 2 apresenta valores menores de evapotranspiração real.

Uma segunda comparação foi realizada considerando como cobertura e uso da terra a silvicultura. De acordo com o conceito de evapotranspiração da cultura $\left(E T_{c}\right)$, foi possível estimar uma aproximação da evapotranspiração para áreas de cultivo de eucalipto, adotando-se o coeficiente de cultura $\left(K_{\mathrm{c}}\right)$. Trata-se de uma aproximação, pois esse conceito considera plantas sem déficit hídrico no solo e com condições de fertilidade suficientes para garantir o desenvolvimento normal da planta, situação não esperada para o mês de aquisição das imagens.

Para realizar o cálculo da $E T_{\mathrm{c}}$ foram escolhidas 35 amostras de áreas reflorestadas com eucalipto, visualmente em pleno crescimento, utilizando-se imagens históricas do Google Earth Pro®. Fez-se a confirmação dessas áreas na imagem Landsat utilizada no presente estudo - composição RGB432, juntamente com a análise do Índice de Área Foliar - IAF. Assim, 23 amostras foram definidas, cada amostra correspondendo a um conjunto de pixels. Para $K_{\mathrm{c}}$, foram considerados dois valores: igual a 1, definido em Allen et al. (1998) e utilizado na maioria dos estudos, segundo Alves (2009); e 0,82, proposto por Alves (2009) e estimado na região do rio Doce para a fase média da cultura. 
As amostras correspondem a dois grupos: Grupo 1 (próximo à Viçosa) e Grupo 2 (próximo à Timóteo). Para o Grupo 1 , utilizou-se a $E T_{0}$ da estação Viçosa e para o Grupo 2, da estação Timóteo.

Nas Figuras 11 e 12 são mostrados os gráficos comparativos dos valores de evapotranspiração da cultura estimados para amostras de eucalipto para $K_{\mathrm{c}}=1$ e $K_{\mathrm{c}}=0,82$, respectivamente, com os valores de evapotranspiração real horária estimados pelo SEBAL - Modelos 1 e 2. Deve-se considerar que o valor de cada amostra constitui a média do conjunto de pixels coletado na amostra, que foi dependente da extensão da cultura. Assumindo condições ótimas para o desenvolvimento da cultura, pode-se dizer que houve sucesso nos dois modelos, principalmente porque se observa uma regularidade entre os valores em cada grupo. Entretanto, observa-se uma diferença nos valores médios entre os dois grupos considerados, representando uma variação espacial do fenômeno, mesmo quando se tem o mesmo tipo de cobertura.

A partir desses resultados, também fica mais claro o comportamento do modelo com correção para a influência do relevo - Modelo 2, que tende a apresentar valores de evapotranspiração real mais baixos. Também se observa um desvio padrão um pouco maior (0,03 para o Modelo 1 e 0,05 para o Modelo 2) nos dois grupos considerados - evidenciando a variação da evapotranspiração em relação ao relevo.

Figura 11 - Comparação da evapotranspiração real horária estimada pelo SEBAL Modelos 1 e 2 com a evapotranspiração da silvicultura, Grupo 1 - próximo à Viçosa.

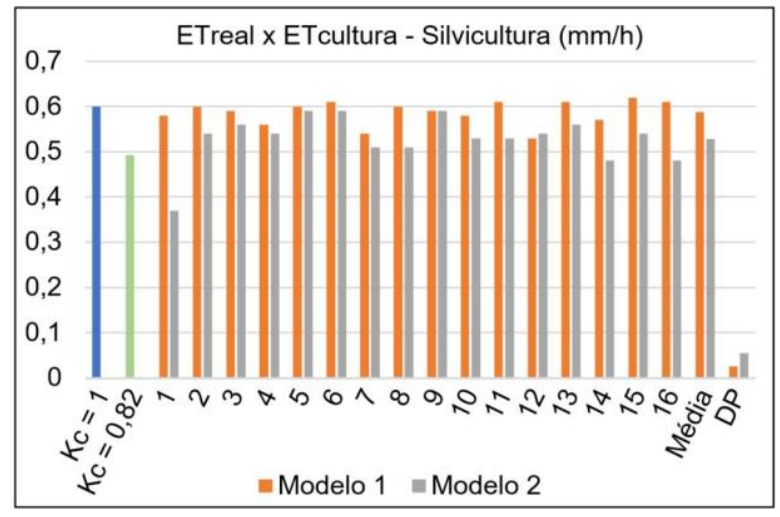

Fonte: Elaborado pelos autores. 
Figura 12 - Comparação da evapotranspiração real horária estimada pelo SEBAL Modelos 1 e 2 com a evapotranspiração da silvicultura, Grupo 2 - próximo à Timóteo.

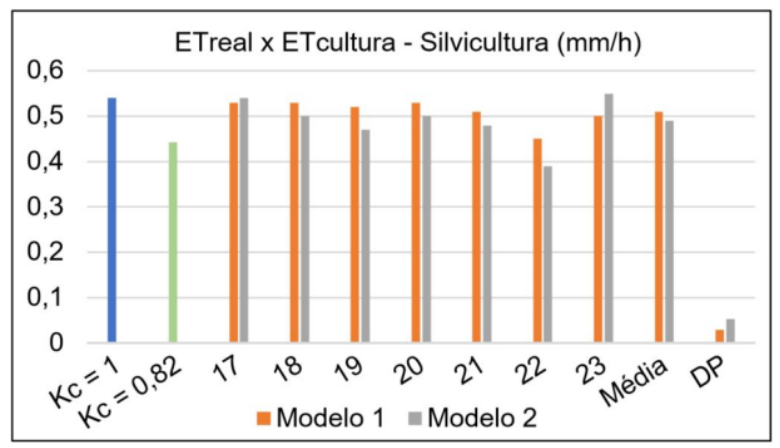

Fonte: Elaborado pelos autores.

Diante dos resultados obtidos, considera-se que a representação da variabilidade da evapotranspiração real no espaço contribui para compreender melhor o comportamento dessa variável em relação aos diversos tipos de cobertura e uso e da terra na área analisada, assim como em relação a outras variáveis, como temperatura da superfície e relevo. Fica evidente também a influência da vegetação, dependendo do ponto de vista fisionômicoestrutural e de suas condições fenológicas de desenvolvimento, na determinação e controle dos fluxos energéticos.

Em relação aos dois modelos aplicados, percebe-se que o Modelo 2 tende a apresentar valores menores e com maior variância em relação ao Modelo 1 , porém, não há evidências sólidas para apontar qual o modelo oferece estimativas mais precisas, o que necessitaria de estudos complementares, com medições em campo e calibrações locais para o SEBAL.

\section{Considerações Finais}

A partir da metodologia proposta e dos resultados obtidos neste estudo, verifica-se que a estimativa da evapotranspiração real horária e diária para a UPGRH DO1 foi alcançada, permitindo a representação da variabilidade espacial dessa variável e a construção de relações com a cobertura e uso e da terra local, considerando a capacidade de contribuição de vapor d'água para a 
atmosfera de cada classe temática mapeada (Água, Floresta/Silvicultura, Vegetação herbácea, Áreas não vegetadas).

Com base nos valores estimados, tem-se que os dados do sistema Landsat 8 foram eficientes para subsidiar a estimativa das diversas variáveis nas quais foram aplicados - albedo da superfície $(\alpha)$, índices de vegetação e temperatura de superfície (Ts). Assim, avalia-se que o SEBAL mostrou ser um procedimento consistente para a estimativa da evapotranspiração a partir do uso de dados de sensoriamento remoto, sendo um complemento àqueles derivados de métodos clássicos.

\section{Agradecimentos}

À CAPES, pelo apoio finaceiro por meio da bolsa de mestrado DEMANDA SOCIAL, Processo 1480978.

Ao convênio de cooperação técnica D05/081/2008, entre o INMET e a UFMG, pela disponibilização dos dados meteorológicos utilizados neste estudo.

À USGS, pela disponibilização dos dados orbitais do satélite Landsat 8.

\section{Referências}

ALLEN, R. G.; PEREIRA, L. S.; RAES, D.; SMITH, M. Crop evapotranspiration: guidelines for computing crop requirements - FAO irrigation and drainage paper 56. Roma: Natural Resources Management and Environment Department, 1998. 300p.

ALLEN, R. G.; TASUMI, M.; TREZZA, R. SEBAL surface energy balance algorithms for land: advanced training and users manual, Idaho implementation. Kimberly: 2002. 98p.

ALLEN, R. G.; TASUMI, M.; TREZZA, R. Satellite-based energy balance for mapping evapotranspiration with internalized calibration (METRIC) - model. Journal of Irrigation and Drainage Engineering, v. 133, n. 4, 2007, pp. 380-394. 
ALVES, L. M.; MARENGO, J. A.; CAMARGO JR., H.; CASTRO, C. Início da estação chuvosa na região Sudeste do Brasil: Parte 1 - Estudos Observacionais. Revista Brasileira de Meteorologia, v. 20, n. 3, 2005, pp. 385-394.

ALVES, M. E. B. Disponibilidade e demanda hídrica na produtividade da cultura do eucalipto. Tese de doutoramento. Universidade Federal de Viçosa, Programa de Pós-Graduação em Meteorologia Agrícola, Viçosa, 2009. $136 f$.

BASTIAANSSEN, W. Regionalization of surface flux densities and moisture indicators in composite terrain: a remote sensing approach under clear skies in Mediterranean climates. Doctoral thesis - Wageningen Agricultural University, Wageningen The Netherlands, 1995. $273 f$.

BASTIAANSSEN, W.; MENENTI, M.; FEDDES, R.; HOLTSLAG, A. A remote sensing surface energy balance algorithm for land (SEBAL) - 1. Formulation. Journal of Hydrology, v. 212, 1998a, pp. 198-212.

BASTIAANSSEN, W.; PELGRUM, H.; WANG, J.; MA, Y.; MORENO, J.; ROERINK, G.; van der WAL, T. A remote sensing surface energy balance algorithm for land (SEBAL) - 2 Validation. Journal of Hydrology, v. 212, 1998b. pp. 213229.

BASTIAANSSEN, W. G. M. SEBAL-based sensible and latent heat fluxes in the irrigated Gediz Basin, Turkey. Journal of Hydrology, v. 229, 2000, pp. 87100.

BORATTO, I. M. P. Espacialização dos componentes do balanço de energia e de evapotranspiração, na região Norte de Minas Gerais, utilizando o modelo SEBAL e imagens orbitais Landsat 5 TM. Dissertação de Mestrado. Pontifícia Universidade Católica de Minas Gerais, Programa de Pósgraduação em Geografia - Tratamento da Informação Espacial, Belo Horizonte, 2012. 129f.

CUPOLILLO, F.; ABREU, M. L.; VIANELLO, R. L. Climatologia da bacia do rio Doce e sua relação com a topografia local. Geografias, v. 4, n. 1, 2008, pp. 45-60.

FEAM - FUNDAÇÃO ESTADUAL DO MEIO AMBIENTE. Plano para incremento do percentual de tratamento de esgotos sanitários da 
bacia hidrográfica do rio Piranga. Belo Horizonte: Fundação Estadual do Meio Ambiente, 2015. 413p. (Volume I).

IBGE - INSTITUTO BRASILEIRO DE GEOGRAFIA E ESTATÍSTICA. Atlas Nacional do Brasil: unidades de relevo do Brasil. Rio de Janeiro: IBGE, 2010. Escala 1: 5.000.000.

IBGE - INSTITUTO BRASILEIRO DE GEOGRAFIA E ESTATÍSTICA. Base cartográfica contínua do Brasil - 1:250.000. 2. ed. Rio de Janeiro: IBGE, 2015. Escala 1:250.000.

IGAM - INSTITUTO MINEIRO DE GESTÃO DAS ÁGUAS. Primeira etapa do plano estadual de recursos hídricos de Minas Gerais: estudos de caracterização dos recursos hídricos do estado de Minas Gerais. Relatório técnico 1, Tecnologia e Consultoria Brasileira S. A., 2007. 177p.

IGAM - INSTITUTO MINEIRO DE GESTÃO DAS ÁGUAS. Unidades de $\begin{array}{llll}\text { Planejamento } & \text { UPGRHS. } & \text { IGAM, }\end{array}$ $<$ http://portalinfohidro.igam.mg.gov.br/mapas-e-bases-cartograficas/basescartograficas/4811-unidades-de-planejamento-upgrhs>, acessado em setembro de 2016.

IGAM - INSTITUTO MINEIRO DE GESTÃO DAS ÁGUAS. Plano de Ação de Recursos Hídricos da Unidade de Planejamento e Gestão DO1 PARH Piranga. Consórcio Ecoplan - Lume, 2010.

IGAM - INSTITUTO MINEIRO DE GESTÃO DAS ÁGUAS. Bases Cartográficas digitais (bacias federais e estaduais). Escala 1:50000 e 1:100000. Site $<$ http://www.igam.mg.gov.br/index.php?option=com_content\&task=view\&id= 90\&Itemid=147>, acessado em 15 janeiro de 2016.

IRACEMA, F. A.; FERREIRA, N. J.; DA SILVA, M. G. A.; DIAS, M. A. F. S (Org.). Tempo e Clima no Brasil. São Paulo: Oficina de Textos, 2009. 463p.

JABER, H. S.; MANSOR, S.; PRADHAN, B.; AHMAD, N. Evaluation of SEBAL Model for Evapotranspiration Mapping in Iraq Using Remote Sensing and GIS. International Journal of Applied Engineering Research, v. 11, n. 6, 2016, pp. 3950-3955.

JIMÉNEZ-BELLO, M. Á.; CASTEL, J. R.; TESTI, L., INTRIGLIOLO, D. S. 
Assessment of a Remote Sensing Energy Balance Methodology (SEBAL) using different interpolation methods to determine evapotranspiration in a citrus orchard. IEEE Journal of Selected Topics in Applied Earth Observations and Remote Sensing, v. 8, n. 4, 2015, pp. 1465-1477.

MAHMOUD, S. H.; ALAZBA, A. A. A coupled remote sensing and the Surface Energy Balance based algorithms to estimate actual evapotranspiration over the western and southern regions of Saudi Arabia. Journal of Asian Earth Sciences, v. 124, 2016, pp. 269-283.

MATHER, P. M. Computer processing of remotely-sensed images: an introduction. $3^{\text {th }}$ ed. Chichester: John Wiley \& Sons, 2004. 324p.

MENEZES, S. J. M. C. Evapotranspiração regional utilizando o SEBAL em condições de relevo montanhoso. Dissertação de Mestrado. Universidade Federal de Viçosa, Programa de Pós-Graduação em Engenharia Agrícola, Viçosa, 2006. 84f.

MIRANDA, E. E.; (Coord.). Brasil em relevo. Campinas: Embrapa Monitoramento por Satélite, 2005.

MKHWANAZI, M.; CHÁVEZ, J.; ANDALES, A. SEBAL-A: A remote sensing ET algorithm that accounts for advection with limited data. Part I: development and validation. Remote Sensing, v. 7, n. 11, 2015, pp. 15046-15067.

NICÁCIO, R. M. Evapotranspiração real e umidade do solo usando dados de sensores orbitais e a metodologia SEBAL na bacia do rio São Francisco. Tese de doutoramento. Universidade Federal do Rio de Janeiro, Programa de Pós-Graduação em Engenharia, Rio de Janeiro, 2008. 320p.

NUNES, L. H.; VICENTE, A. K.; CANDIDO, D. H. Clima da região Sudeste do Brasil. In: CAVALCANTI, I. F. A.; FERREIRA, N. J.; SILVA, M. G. A. J.; DIAS, M. A. F. (Org.). Tempo e clima no Brasil. São Paulo: Oficina de Textos, 2009. $463 p$.

PEREIRA, A. R.; SEDIYAMA, G. C.; VILLA NOVA, N. A. Evapotranspiração. Campinas: Fundag, 2013. 323p.

PROFETA, A. L. Estimativa da evapotranspiração real em área de relevo acidentado utilizando o SEBAL. Dissertação de Mestrado. Universidade 
Federal de Minas Gerais, Programa de Pós-Graduação em Análise e Modelagem de Sistemas Ambientais, Belo Horizonte, 2017. $80 f$.

RUHOFF, A. L. Sensoriamento remoto aplicado à estimativa da evapotranspiração em biomas tropicais. 2011. Tese de doutoramento. Universidade Federal do Rio Grande do Sul, Programa de Pós-Graduação em Recursos Hídricos e Saneamento Ambiental, Porto Alegre, 2011. $162 f$.

SILVA, B. B. da; WILCOX, B. P.; SILVA, V. P. R. da; MONTENEGRO, S. M. G. L.; OLIVEIRA, L. M. M. de. Changes to the energy budget and evapotranspiration following conversion of tropical savannas to agricultural lands in São Paulo State, Brazil. Ecohydrology, v. 8, n. 7, 2015, pp. 1272-1283.

STEELE, D. D.; THORESON, B. P.; HOPKINS, D. G. CLARK, B. A.; TUSCHERER, S. R.; GAUTAM, R. Spatial mapping of evapotranspiration over Devils Lake basin with SEBAL: application to flood mitigation via irrigation of agricultural crops. Irrigation Science, v. 33, n. 1, 2014, pp. 15-29.

TASUMI, M.; ALLEN, R. G.; TREZZA, R. At-Surface Reflectance and Albedo from Satellite for Operational Calculation of Land Surface Energy Balance. Journal of Hydrologic Engineering, v. 13, n. 2, 2008, pp. 51-63.

TEIXEIRA, A.H. C.; BASTIAANSSEN, W.G.M.; AHMAD, M.D.; MOURA, M.S.B.; BOS, M.G. Analysis of energy fluxes and vegetation-atmosphere parameters in irrigated and natural ecosystems of semi-arid Brazil. Journal of Hydrology, v. 362 , n. 1-2, 2008, pp. 110-127.

TEIXEIRA, A.H. C.; BASTIAANSSEN, W.G.M.; AHMAD, M.D.; BOS, M.G. Reviewing SEBAL input parameters for assessing evapotranspiration and water productivity for the low-middle São Francisco river basin, Brazil: part B: application to the regional scale. Agricultural and Forest Meteorology, v. 149, n. 3-4, 2009, pp. 477-490.

UFV - UNIVERSIDADE FEDERAL DE VIÇOSA; CETEC - FUNDAÇÃO CENTRO TECNOLÓGICO DE MINAS GERAIS; UFLA - UNIVERSIDADE FEDERAL DE LAVRAS; FEAM - FUNDAÇÃO ESTADUAL DO MEIO AMBIENTE. Mapa de solos do Estado de Minas Gerais. Belo Horizonte: Fundação Estadual do Meio Ambiente, 2010. 
USGS - UNITED STATES GEOLOGICAL SURVEY. Landsat 8 (L8) data users

handbook. Version 1. Sioux Falls: Earth Resources Observation and Science (EROS), 2015a. 97p.

USGS - UNITED STATES GEOLOGICAL SURVEY. Product guide: provisional

Landsat 8 surface reflectance product. Versão 1.8, $2015 \mathrm{~b}$.

USGS - UNITED STATES GEOLOGICAL SURVEY. Product guide: Landsat 8 surface reflectance code (LaSRC) product. Versão 3. 2016.

VERMOTE, E.; JUSTICE, C.; CLAVERIE, M.; FRANCH, B. Preliminary analysis of the performance of the Landsat 8/OLI land surface reflectance product. Remote Sensing of Environment, v. 185, 2016, pp. 46-56.

ZHOU, X.; BI, S.; YANG, Y.; TIAN, F.; REN, D. Comparison of ET estimations by the three-temperature model, SEBAL model and eddy covariance observations. Journal of Hydrology, v. 519, 2014, pp. 769-776. 